\title{
Hospital admissions for non-communicable disease in the UK military and associations with alcohol use and mental health: a data linkage study
}

L. Goodwin ${ }^{1,2,3^{*}}$ (D, D. Leightley², Z. E. Chui ${ }^{2}$, S. Landau 4 , P. McCrone ${ }^{5}$, R. D. Hayes ${ }^{6}$, M. Jones ${ }^{2}$, S. Wessely ${ }^{2,7}$ and N. T. Fear ${ }^{2,7}$

\begin{abstract}
Background: Since the recent conflicts in Iraq and Afghanistan, the short-term focus of military healthcare research has been on the consequences of deployment for mental health and on those wounded or injured in combat. Now that these conflicts have ended for the UK Armed Forces, it is important to consider the longer term physical and mental health consequences, and just as importantly, the links between these. The aims of this study were to determine the most common physical conditions requiring a hospital admission in UK military personnel and whether they were more common in personnel with a mental health condition, smokers, and/or those misusing alcohol compared to those without.

Methods: Data linkage of a prospective UK military cohort study to electronic admitted patient care records for England, Wales and Scotland. Nine thousand nine hundred ninety military personnel completed phase 2 of a military cohort study (56\% response rate, data collected from 2007 to 2009), with analyses restricted to $86 \%$ of whom provided consent for linkage to healthcare records $(n=8602)$. Ninety percent were male and the mean age at phase 2 was 36 years. The outcome was physical non communicable diseases (NCDs) requiring a hospital admission which occurred after phase 2 of the cohort when the mental health, smoking and alcohol use exposure variables had been assessed until the end of March 2014.

Results: The most common NCDs requiring a hospital admission were gastrointestinal disorders 5.62\% (95\% Confidence Intervals (Cl) 5.04,6.19) and joint disorders 5.60\% (95\% Cl 5.02, 6.18). Number of NCDs requiring a hospital admission was significantly higher in those with a common mental disorder (Hazard ratio (HR) 1.40 (95\% Cl 1.16-1.68), post-traumatic stress disorder (HR 1.78 (95\% Cl 1.32-2.40)) and in current smokers (HR 1.35 (95\% Cl 1.12-1.64) compared to those without the disorder, and non-smokers, respectively.

\footnotetext{
* Correspondence: laura.goodwin@liverpool.ac.uk

'Department of Psychology, University of Liverpool, Room 2.31 Eleanor Rathbone Building, Liverpool L69 7ZA, UK

${ }^{2}$ King's Centre for Military Health Research, Institute of Psychiatry, Psychology

\& Neuroscience, King's College London, London, UK

Full list of author information is available at the end of the article
}

(c) The Author(s). 2020 Open Access This article is licensed under a Creative Commons Attribution 4.0 International License, which permits use, sharing, adaptation, distribution and reproduction in any medium or format, as long as you give appropriate credit to the original author(s) and the source, provide a link to the Creative Commons licence, and indicate if changes were made. The images or other third party material in this article are included in the article's Creative Commons licence, unless indicated otherwise in a credit line to the material. If material is not included in the article's Creative Commons licence and your intended use is not permitted by statutory regulation or exceeds the permitted use, you will need to obtain permission directly from the copyright holder. To view a copy of this licence, visit http://creativecommons.org/licenses/by/4.0/ The Creative Commons Public Domain Dedication waiver (http://creativecommons.org/publicdomain/zero/1.0/) applies to the data made available in this article, unless otherwise stated in a credit line to the data. 
(Continued from previous page)

Conclusions: Military personnel with a mental health problem are more likely to have an inpatient hospital admission for NCDs compared to those without, evidencing the clear links between physical and mental health in this population.

Keywords: Military, Armed forces, Cohort study, Data linkage, Electronic healthcare records, Non-communicable disease, Alcohol use, Mental health, Post-traumatic stress disorder

\section{Background}

Since the recent conflicts in Iraq and Afghanistan, the short-term focus of military healthcare research for the Coalition Forces who participated has been on the consequences of deployment for mental health $[1,2]$ and on those wounded or injured in combat [3]. Now that these conflicts have ended for the UK Armed Forces (AF), it is important to consider the longer term physical and mental health consequences, and just as importantly, the links between these [4].

Comparisons of the physical health of serving and exserving personnel to the general population have provided contrasting findings. The most recent data from the U.S. Veterans Eligibility Trends and Statistics showed that life expectancy is shorter by approximately 1 year for ex-serving personnel compared to the general U.S. population, and additionally found the same socioeconomic patterning as in the general population, with higher mortality rates in ex-serving personnel with a lower educational attainment and lower household income [5]. This is supported by evidence that ex-serving personnel report more chronic conditions compared to non-veterans [6] and have an increased risk of coronary heart disease [7], attributed to historically higher rates of smoking [8]. Musculoskeletal disorders and arthritis are also more common in ex-serving personnel than in civilians [9].

Conversely, a healthy warrior or solider effect has been proposed to result from the screening and selection processes that occurs at enlistment. A meta-analysis quantified this theory, with an overall protective effect for allcause mortality ranging from 10 to $25 \%$, in ex-serving personnel compared to the general population [10] but reported no difference in the UK studies $[11,12]$. However, the healthy warrior effect is likely to reduce over time, particularly if there are exposures through military service associated with longer term worsening of physical health.

It is crucial that we take a nuanced approach when examining the type of physical health conditions reported, given that increased all-cause mortality in exserving personnel may be explained by specific causes [13]. The current study will focus on hospital admissions for non-communicable diseases (NCDs), which account for approximately two thirds of deaths globally, most commonly due to cardiovascular diseases [14] and provide much needed evidence on the links between mental health and physical NCDs in the UK AF. Much of the data on the physical health of ex-serving personnel has been recorded through US Veterans Affairs (VA) healthcare services [15] (most likely because visits are recorded for payment purposes), or from studies which use self-reports of physical health [16]. VA reports suggest that the most common conditions are hypertension, followed by arthritis, diabetes and ischaemic heart disease [17]. Combat personnel appear to have an additional health burden compared to non-combat exposed personnel, for example with an increased risk of chronic pain and stroke [18] and increased levels of inflammatory markers in trauma exposed Israeli combat ex-serving personnel [19].

There are a number of reasons why the risk of NCDs could be high in serving and ex-serving personnel. First, there is the consequence of serving in a physical demanding occupation (e.g. for musculoskeletal conditions [20]), in addition to the specific health impacts of deploying to challenging environments [21]. Second, there may be predisposing risk factors, relating to higher levels of recruitment to the AF from areas of greater deprivation, associated with a greater risk of childhood adversity [22]. Third, alcohol is consistently identified to be a problem in military populations [23, 24], with an established health burden [25], but an increased smoking prevalence is not consistent across countries [26, 27]. Whilst levels of exercise are found to be higher in serving personnel, they decrease after leaving service [26] with generally poor cardiovascular health metrics in exserving personnel [28]. Finally, the mental health of serving personnel appears to be worse than civilians [29], with known physical health consequences.

In keeping with a vast civilian literature, the physical health of ex-serving personnel with a mental health problem is poorer; personnel with post-traumatic stress disorder (PTSD) are more likely to have musculoskeletal, neurological, and gastrointestinal disorders compared to those without PTSD [30]. Behavioural and biological mechanisms have been evidenced to explain the links between PTSD and cardiovascular health, with a strong role of health behaviour risks, such as alcohol and smoking [31]. Depression is linked to an increased risk of mortality in general population studies [32] and 
specifically to musculoskeletal disorders in veterans, with proposed explanatory factors including chronic pain and physical inactivity [33-35]. Of significance to the current study is the finding that US ex-serving personnel with a mental disorder have a higher number of all cause hospitalisations [36].

The current study focuses on which NCDs (requiring inpatient hospital care) are most common in a UK military population. It will use secondary healthcare records from England, Wales and Scotland, linked to the King's Centre for Military Health Research (KCMHR) military cohort $[1,37]$ to identify the healthcare records of a large representative sample of military personnel. It is also the first study of which we are aware to analyse secondary datasets from England, Wales and Scotland together [38]. This paper reports on: 1) the most common NCDs requiring a hospital admission in the UK military; 2) how i) self-reports of alcohol misuse, smoking and mental health problems (reported before the outcomes) and ii) change in alcohol use and mental health are associated with NCDs requiring an admission after adjustment for sociodemographic factors, military characteristics and childhood adversity. Additional analyses will 3) examine the adjusted association between alcohol misuse, smoking and mental health with the total number of NCDs requiring an admission and 4) will conduct age standardised comparisons to publicly available data on NCDs requiring a hospital admission in England in the general population.

\section{Methods}

\section{Study design}

Data linkage was conducted between a large UK military cohort study and electronic secondary healthcare records for admitted patient care in England, Wales and Scotland [38]. The exposures were measured at phases 1 [37] and 2 [1] of the cohort study (described below) and outcomes were reported in the healthcare records from the phase 2 questionnaire completion date onwards until the end of March 2014 (See Supplementary figure 1).

\section{Data}

\section{King's Centre for Military Health Research cohort study}

The KCMHR cohort is a large representative study of military personnel. Data were collected in 2004-2006 (phase 1) and again in 2007-2009 (phase 2). Phase 1 recruited approximately $10 \%$ of UK military personnel who had been deployed to the first phase of the Iraq war, and a further sample who had not been deployed to Iraq. Ten thousand two hundred seventy-two participants in total responded (8686 Regulars, 1586 Reservists; $59 \%$ response rate) [37]. For phase 2 data collection (2007-2009), 9395 participants from phase 1 were available for follow-up. Six thousand four hundred twenty- nine completed the phase 2 data collection (68\% response rate). Response at phase 2 was associated with being older, female, an officer and a regular (and so these factors were included in the development of the survey response weights). There were two additional samples at phase 2; with 896 personnel recruited who had deployed to Afghanistan (response rate 50\%) and 2665 individuals responding who had joined the military between April 2003 and April 2007 (response rate 40\%). In total, 9990 individuals completed the phase 2 questionnaire (overall response rate 56\%) [1]. Individuals who took part at phase 1 only are not included in the analyses and $86 \%$ of the phase 2 participants provided consent for linkage to healthcare records $(n=8602)$.

\section{Socio-demographic, pre-military, military and health characteristics from the KCMHR cohort}

Socio-demographic variables Demographic information available was sex, age (at time of phase 2 questionnaire) and marital status at phase 2 (categorised as single or in a relationship/married or separated/divorced/ widowed).

Military characteristics Self-reported at phase 2 were military rank (Other ranks/non-commissioned Officer or Officer rank), status (regular or reservist), service (Naval Services or Army or Royal Air Force), serving status (Serving or ex-serving at phase 2), role in parent unit (combat, combat service support or combat support) and most recent deployment (including data on last deployment to Iraq or Afghanistan (or both)) were used.

Pre-military characteristics (childhood adversity) A measure of family relationship childhood adversity was assessed [39] (either at phase 1 or 2 dependent on when personnel joined the cohort), adapted from the Adverse Childhood Exposure study scale [40]. This included 8 items which were summed to form a cumulative measure and analysed as 0/1,2/3 and $4+$ adversities.

Smoking Smoking status and frequency were assessed through a self-report at phase 2 categorised as exsmoker, non-smoker and current smoker.

Mental health and alcohol use at phases $1 \& 2$ The General Health Questionnaire (GHQ-12) was used to screen for symptoms of common mental disorder (CMD), providing a general assessment of current psychological distress [41, 42]. Examples of items include 'feeling unhappy or depressed' and 'feeling constantly under strain'. For this study the bi-modal scoring method of $0-0-1-1$ was used, with those endorsing a negative symptom as 'rather' or 'much more than usual', 
or a positive symptom as 'less' or 'much less than usual', classified as reporting a symptom. Scores for the full scale ranged from 0 to 12 and a $>=4$ cut-off was used to represent probable CMD. Symptoms of PTSD (in line with the Diagnostic and Statistical Manual of mental disorders (DSM-IV) [43]) were assessed by the National Centre for PTSD Checklist - Civilian version (PCL-C [44];); a 17-item questionnaire assessing five reexperiencing, seven avoidance and five hyperarousal symptoms, which has previously been used in military populations [1]. The PCL-C was used in preference to the military version because it is less restrictive in considering traumatic events unrelated to deployment. Cases were defined as individuals with a total score of 50 or above, referred to as 'probable PTSD'. Alcohol use was measured by the 10-item World Health Organization (WHO) Alcohol Use Disorders Identification Test [45]. A score of 0-7 was classified as low risk drinking, 8-15 indicated hazardous use, a score of 16 or more was used to define harmful alcohol misuse (hazardous use, likely to be harmful to health) and individuals who reported currently never drinking were categorised separately (when cell sizes where large enough, otherwise this category was combined with low risk drinking). A single item from the AUDIT was used to characterise binge drinking "How often do you have six or more drinks on one occasion?", with those endorsing 6 or more units weekly or more defined as a binge drinker. The main analyses only included these variables assessed at phase 2 as the exposure variables. Variables reflecting change in mental health/alcohol status from phase 1 to 2 were derived for CMD and alcohol misuse (but not for PTSD due to low numbers). These all included 4 categories: no case stable, case stable (at both phases), positive change (from case to no case) and negative change (no case to case).

\section{Hospital admissions in electronic healthcare records (EHRs)}

Secondary care visits for physical health conditions for regulars, reservists and veterans take place either through Ministry of Defence Hospital Units that are hosted within National Health Service (NHS) hospitals or directly through NHS hospitals (including visits commissioned by the Ministry of Defence). This study combined three NHS datasets from NHS Digital (for Hospital Episode Statistics; HES), Information Services Division (ISD) and Secured Anonymised Information Linkage (SAIL) which cover all NHS secondary care in England, Scotland and Wales, respectively. The EHR data were requested for the financial years 2003/04 to $2013 / 2014$ (in order to cover the timescale of the KCMHR cohort study with some follow-up after phase 2 ). The outcomes assessed in the current study were restricted to those occurring in admitted patient care (APC) episodes as outpatient and accident \& emergency data did not have acceptable completion of formalised diagnosis codes [38]. For the survival analyses, an event was considered as occurring from the time of the phase 2 questionnaire onwards and individuals with the event between phases 1 and 2 were excluded.

\section{Data linkage \\ Linkage of the administrative dataset for the cohort participants to EHRs}

A dataset of unique patient identifiers including NHS number, forename, surname, sex and date of birth, and a unique scrambled cohort identifier to allow for linkage back to the cohort, was provided to each of the three Nations [38]. Linkage was conducted separately by NHS Digital for England, NHS Information Services for Wales and ISD for Scotland, using different matching procedures (see $[46,38]$ for additional details on the linkages).

\section{Integrating the EHRs}

Records and episodes relating to APC events for the separate HES, SAIL and ISD datasets were combined for variables which were co recorded across all three $\mathrm{Na}$ tions, including primary and secondary diagnoses coded to International Classification of Diseases, 10th revision (ICD-10, [47, 48]). The combined EHR data from across the Nations was then merged to the KCMHR cohort data using the scrambled cohort identifier.

\section{Data access and cleaning methods}

A number of data checks were conducted, including checking admission and discharge dates for chronological consistency. Diagnoses for each participant were reviewed and the first chronological occurrence of a diagnosis was identified and these data were stored in a date format.

\section{Bias}

Efforts were taken to reduce potential sources of bias by comparing any differences between the matched and unmatched samples. This suggested that the greatest difference between these samples was by presence of NHS number, which would be expected given this was used in the matching process. The final analyses used the full consented sample $(n=8602)$ as the denominator for analyses, rather than only those who were matched $(n=$ 6336). This takes a potentially conservative approach in reporting prevalence estimates and associations, rather than over inflating estimates if the matched sample were more likely to have a secondary care event (personnel with an NHS number were both more likely to be matched and may also have been more likely to have visited an NHS organisation). However, the key analyses 
reported in Table 4 were repeated as sensitivity analyses in the matched only sample and the differences in the results compared to analysing the full sample were very minimal (results reported in Supplementary table 2).

Health outcomes in the electronic healthcare records Diagnoses across England, Wales and Scotland were coded using the three-character (ICD-10, [47]) categories which either group diagnoses that share common characteristics or represent single conditions [49]. The health outcomes of interest in the current study were physical non-communicable diseases (NCDs), identified in the healthcare records using the relevant ICD-10 codes. There is no generic framework of NCDs recommended for electronic healthcare records, so a systematic review was conducted to identify which NCDs codes to extract (ICD-10). This review resulted in a framework of 28 non-communicable physical conditions (which excluded infectious disease, mental health disorders and conditions relating to reproduction and fertility) under ten disease categories (reported in Supplementary file 1).

\section{Data analysis}

This study included the full sample of those who consented to allow access to their medical records $(n=$ 8602). Combined sampling weights accounted for both the over-sampling of particular groups (e.g. reservists) at phase 1 and the probability weights of non-response at phase 2. All frequencies were unweighted and weighted proportions and weighted model estimates were reported using the survey commands in STATA v.14 [50]. A complete case analysis approach was used. Missing data on the exposure and confounding variables from the KCMHR cohort data (which all 8602 participants completed) ranged from 0 to $1.1 \%$. Cell sizes less than 8 were not reported according to NHS Digital guidelines [51].

1. Frequencies and weighted $\%$ were calculated for the full consented sample $(n=8602)$ and the matched $(n=6336)$ and unmatched samples $(n=2266)$ for all socio-demographics, military characteristics, childhood adversity, and smoking, alcohol and mental health variables (Supplementary table 1). Weighted Chi square $\left(x^{2}\right)$ analyses were conducted comparing the matched sample with those who were not matched. The Pearson $\chi^{2}$ statistic with the Rao and Scott [52] second-order correction was presented (Supplementary table 1).

2. Weighted proportions and $\mathbf{9 5 \%}$ confidence intervals were calculated for all 28 NCDs requiring a hospital admission from the new framework, with the top 10 presented ordered by proportion. These were first calculated for any events which occurred across the full study period, between 2003/04 to 2013/14, and were then calculated for events occurring after the date of phase 2 questionnaire completion. The sample included all participants who had consented to their hospital records to be matched, minus those individuals with the event before the date they completed the phase 2 questionnaire (Table 1).

3. The top $\mathbf{5}$ NCDs were cross tabulated with all of the sociodemographic, military characteristics and childhood adversity, and- unweighted frequencies, weighted $\%$ and confidence intervals are reported. Unadjusted weighted Cox regression analyses identified where there were statistically significant associations with these potential confounding variables and the NCD outcomes, restricted to NCD events that occurred after the completion of the phase 2 questionnaire and using the date of the admission as the outcome. The median number of total NCDs (out of the 28 NCDs studied) was calculated overall and then selecting individuals separately with each of the top 5 NCDs (Table 2).

4. Age standardised comparisons with the general population for England - For the top 5 conditions, frequency data from HES (England only) were compared to publicly available HES data for the combined ICD-10 code categories (stratified by age). Age standardised proportions in the military and general population data were calculated and then used to calculate numbers per 1000 for both populations (these data were restricted to men only for prostate disorders). Publicly available HES data was not available stratified by both gender and age together, which is why only the age standardised data were presented.

5. Weighted negative binomial regression models were conducted with the number of NCD conditions occurring after phase 2 as the outcome $(\boldsymbol{n}=\mathbf{8 5 1 8})$. Number of NCDs was treated as a non-normally distributed count variable and reflected the number of NCDs requiring an inpatient admission after phase 2, with mental health, alcohol use and smoking status the exposure variables in the models. Participants with an admission for any NCD before phase 2 and with no admissions after phase 2 were excluded from this analysis, as the analyses aimed to predict new NCD events after phase 2 . The models were tested in a number of steps, i) unadjusted models, ii) adjusted for age, gender, marital status and military characteristics (rank, serving status, engagement type, service branch, deployment to Iraq or Afghanistan and primary role in parent unit), iii) 
Table 1 The top 10 NCDs in the full sample $(n=8602)$ ordered by \% (overall and after completion of phase 2 questionnaire)

\begin{tabular}{|c|c|c|c|c|c|c|}
\hline Rank & Events overall $(n=8602)$ & $\mathrm{n}$ & Weighted \% (95\% Cl) & $\begin{array}{l}\text { New events after phase } 2 \\
\text { ( } \mathrm{n} \text { differs by condition) }^{\mathrm{a}}\end{array}$ & $\mathrm{n}$ & Weighted \% $(95 \% \mathrm{Cl})$ \\
\hline 1 & Gastrointestinal Disorders & 482 & $5.62(5.04,6.19)$ & Gastrointestinal Disorders & $303 / 8423$ & $3.64(3.17,4.12)$ \\
\hline 2 & Other Joint Disorders & 467 & $5.60(5.02,6.18)$ & Other Joint Disorders & $291 / 8426$ & $3.38(2.93,3.83)$ \\
\hline 3 & Arthritis/osteoarthritis & 183 & $2.18(1.82,2.55)$ & Arthritis/osteoarthritis & $131 / 8550$ & $1.54(1.23,1.85)$ \\
\hline 4 & Hypertension & 151 & $2.02(1.66,2.37)$ & Hypertension & $105 / 8556$ & $1.38(1.09,1.68)$ \\
\hline 5 & $\begin{array}{l}\text { Prostate and other } \\
\text { genitourinary disorder }\end{array}$ & 158 & $1.94(1.59,2.29)$ & $\begin{array}{l}\text { Prostate and other } \\
\text { genitourinary disorder }\end{array}$ & $90 / 8534$ & $1.14(0.87,1.41)$ \\
\hline 6 & Asthma/COPD & 130 & $1.59(1.27,1.91)$ & Asthma/COPD & $88 / 8560$ & $1.01(0.76,1.26)$ \\
\hline 7 & Back and neck pain & 123 & $1.56(1.25,1.88)$ & Back and neck pain & $76 / 8555$ & $0.92(0.68,1.16)$ \\
\hline 8 & Cancer and Tumours & 99 & $1.30(1.01,1.59)$ & Cancer and Tumours & $67 / 8570$ & $0.89(0.65,1.14)$ \\
\hline 9 & Migraine/headache & 88 & $1.00(0.75,1.25)$ & Hyperlipidaemia & $55 / 8589$ & $0.72(0.51,0.94)$ \\
\hline 10 & Hyperlipidaemia & 68 & $0.90(0.66,1.14)$ & Migraine/headache & $53 / 8567$ & $0.68(0.47,0.89)$ \\
\hline
\end{tabular}

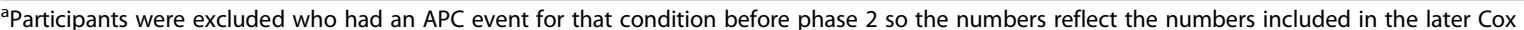
regression analyses

additionally adjusted for family relationship adversity in childhood, and iv) the models with probable PTSD and CMD as the key exposures were additionally adjusted for alcohol misuse and smoking status at phase 2 .

6. Weighted cox proportional hazards models were conducted for each of the top 5 NCD outcomes - The outcome for the models was the date for the first event for each NCD that occurred after the completion of the phase 2 questionnaire and the regressions examined mental health, alcohol use and smoking status as the exposures in the models. The adjustments were the same as for the negative binomial regression models in 5) with adjustments i)-iv). Any participants with the NCD event before phase 2 were excluded from the analyses. Checks for proportional hazards assumptions were tested using Schoenfeld residuals. If the global $\chi^{2}$ test was statistically significant, this indicated that the proportional hazards assumption had been violated. All of the global $\chi^{2}$ tests were found to be non-significant.

7. Weighted Cox regression models were conducted restricted to participants who completed both phases 1 and 2 of the cohort $(n=5794)$ to examine change in CMD status across phase 1 and 2 as the exposure (numbers were too low to run change models for probable PTSD and alcohol misuse). Change was categorised as not a case stable (did not meet criteria at phase 1 or 2 ), case stable (met criteria both phases), positive change (met criteria at phase 1 but not at phase 2) and negative change (did not meet criteria at phase 1 but did by phase 2). The adjustments were the same as for the previous models in 2) and 6).

\section{Results}

Overview of the data linkage

The overall number of participants from the cohort matched to electronic healthcare records from either England, Wales or Scotland was 6336 (73\%). Participants who were matched were more likely to have a NHS number (Supplementary table 1), with only a small number matched without an NHS number in Wales and Scotland due to differences in the approaches utilised. The matching process for England required an NHS number. Of the total number of individuals matched, 4460 were matched in England only (71\%), 257 were matched in Wales only (4\%), 826 in Scotland only (13\%) and 793 were matched in more than one region (12\%). Younger personnel, personnel in the Army, who reported a previous deployment to Iraq and those in a combat role in their parent unit were more likely to be matched. Those who reported childhood antisocial behaviour, who met the criteria for harmful alcohol use on the AUDIT and who self-reported a CMD were also more likely to be matched (Supplementary table 1 ), probably because they were more likely to have used NHS services.

\section{Overview of the sample}

The full sample (Table 2 and Supplementary Table 1) were on average aged 36 years at the time of the phase 2 questionnaire and could have been up to approximately 8 years older by the time of hospital admission. Ninety percent were male and $78 \%$ married or in a relationship. Twenty percent were of Commissioned Officer rank and $28 \%$ had left the services by phase 2 . Fifty six percent had previously deployed to Iraq or Afghanistan, or to both, and $24 \%$ held a combat role in their parent unit. Thirty five percent reported 2 or more family relationship adversities in childhood. Forty three percent of the sample met AUDIT criteria for hazardous drinking and 


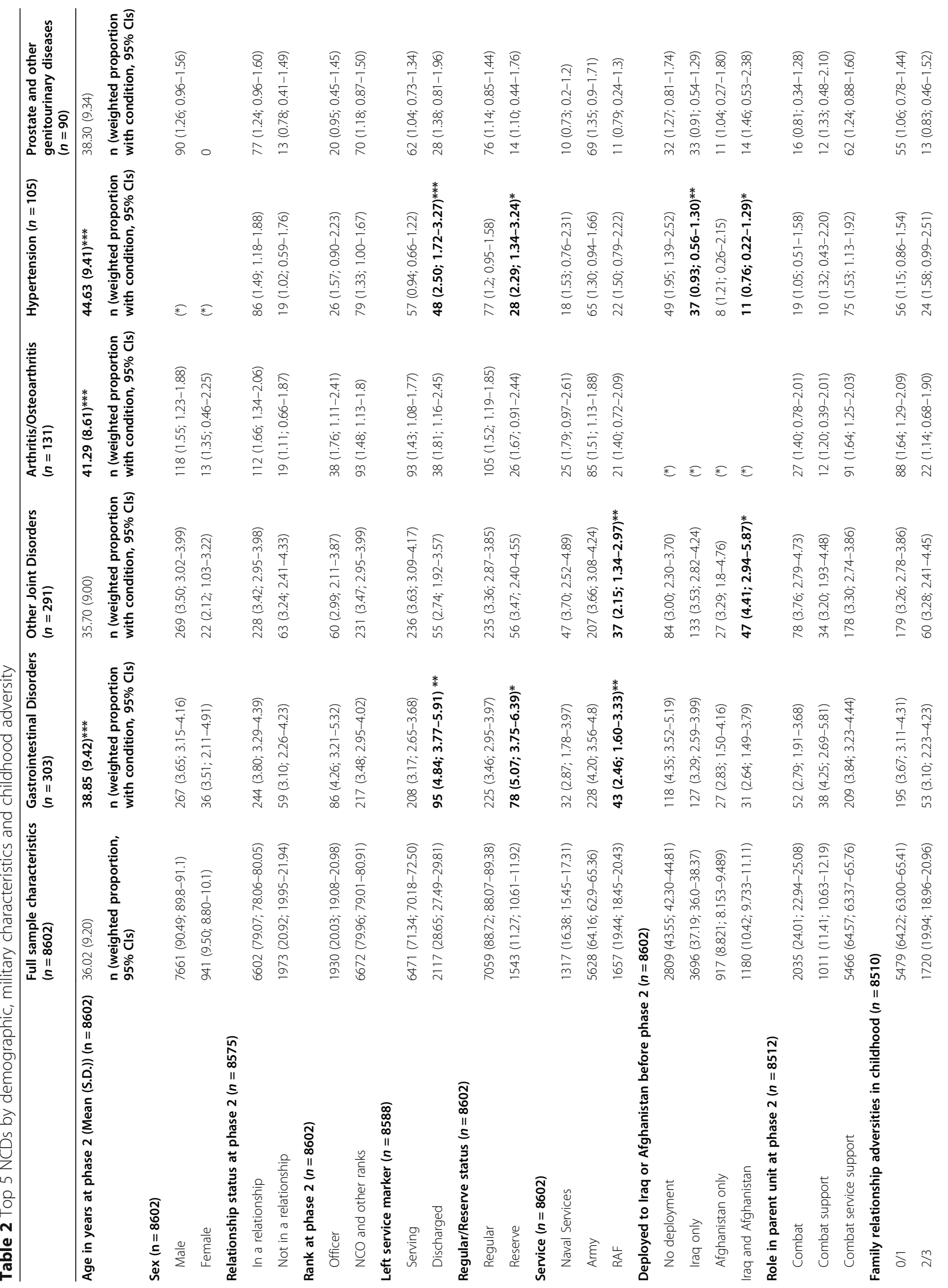




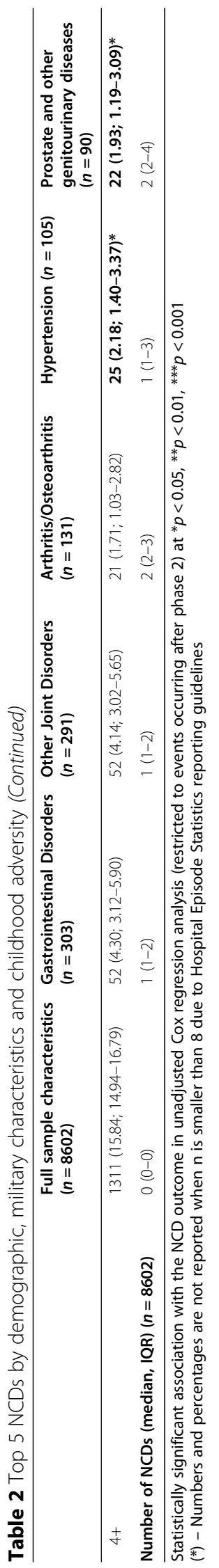


13\% met criteria for harmful drinking. Binge drinking was very common, with $38 \%$ binge drinking more than weekly. Twenty four percent were current smokers. Four percent met criteria for probable PTSD and $20 \%$ of the sample for a CMD.

\section{Healthcare use (admitted patient care)}

Thirty nine percent of the analysed sample had an APC event. As expected, the majority of APC events were at English hospitals, with 36,4 and $5 \%$ of the sample having APC events at English, Welsh and Scottish hospitals, respectively.

\section{Top 10 non-communicable diseases}

The median number of NCDs requiring a hospital admission in the full sample was zero. The most common NCDs requiring an admission in the full sample were gastrointestinal (GI) disorders and joint disorders, both over 5\% (Table 1). The next frequent were arthritis/ osteoarthritis (2\%), prostate and genitourinary (GU) disease $(2 \%)$ and hypertension (2\%). Cancer and tumours was the eighth most common (1\%). When restricted to admissions which occurred after completion of the phase 2 questionnaire, the proportions were lower but the order stayed the same, other than for migraine/headaches and hyperlipidaemia for which the order reversed.

GI disorders were more common in older personnel, those who had left services, reserves, personnel who had served for 12 or more years and less likely in personnel in the Royal Air Force (Table 2). Joint disorders were less common in personnel in the RAF and more common in those who had deployed to both Iraq \& Afghanistan. Arthritis and osteoarthritis were more common in older personnel and those who had served for more than 12 years. Prostate and GU disorders were less common in personnel who were single and with four or more family relationship adversities in childhood. Hypertension was more common in older personnel, those who had left service, reserves, those with longer military service, and in those who reported four or more family relationship adversities in childhood. Hypertension was less common in those who had deployed to Iraq or to both Iraq and Afghanistan.

Table 3 Negative binomial regression models showing the association between mental health, alcohol misuse and smoking with number of NCDs $(n=8452)$

\begin{tabular}{|c|c|c|c|c|c|}
\hline & $\begin{array}{l}\text { Median number } \\
\text { of NCDs (IQR) }\end{array}$ & $\begin{array}{l}\text { Unadjusted } \\
\text { Incidence } \\
\text { Rate Ratio (IRR) } \\
(95 \% \mathrm{Cl})\end{array}$ & $\begin{array}{l}\text { Adjusted IRR } \\
(95 \% \mathrm{CI})^{\mathrm{b}}\end{array}$ & $\begin{array}{l}\text { Adjusted IRR } \\
(95 \% \mathrm{CI})^{\mathrm{c}}\end{array}$ & $\begin{array}{l}\text { Adjusted IRR } \\
(95 \% \mathrm{CI})^{\mathrm{d}}\end{array}$ \\
\hline \multicolumn{6}{|l|}{ PTSD } \\
\hline Non-case & $1(1-2)$ & 1.00 & 1.00 & 1.00 & 1.00 \\
\hline Case & $1(1-2)$ & $1.86(1.39-2.48)$ & $1.91(1.42-2.56)$ & $1.78(1.34-2.37)$ & $1.78(1.32-2.40)$ \\
\hline \multicolumn{6}{|l|}{ CMD } \\
\hline Non-case & $1(1-2)$ & 1.00 & 1.00 & 1.00 & 1.00 \\
\hline Case & $1(1-2)$ & $1.35(1.12-1.61)$ & $1.41(1.19-1.69)$ & $1.38(1.16-1.65)$ & $1.40(1.16-1.68)$ \\
\hline \multicolumn{6}{|l|}{ Alcohol misuse } \\
\hline Current never drinkers & $2(1-2)$ & $1.13(0.67-1.92)$ & $1.22(0.68-2.20)$ & $1.21(0.67-2.18)$ & \\
\hline Low risk drinking $(0-7)$ & $1(1-2)$ & 1.00 & 1.00 & 1.00 & \\
\hline Hazardous drinking (8-15) & $1(1-2)$ & $0.87(0.73-1.04)$ & $1.00(0.84-1.19)$ & $1.00(0.84-1.18)$ & \\
\hline Harmful drinking/possible dependence (16+) & $1(1-1)$ & $0.76(0.60-0.97)$ & $1.03(0.80-1.31)$ & $1.02(0.80-1.31)$ & \\
\hline \multicolumn{6}{|l|}{ Binge drinking at phase 2} \\
\hline Monthly or less & $1(1-2)$ & 1.00 & 1.00 & 1.00 & \\
\hline Weekly or more & $1(1-2)$ & $0.84(0.71-0.99)$ & $0.95(0.81-1.11)$ & $0.96(0.81-1.12)$ & \\
\hline \multicolumn{6}{|l|}{ Smoking status at phase 2} \\
\hline Non-smoker & $1(1-2)$ & 1.00 & 1.00 & 1.00 & \\
\hline Ex-smoker & $1(1-2)$ & $1.28(1.07-1.52)$ & $1.22(0.94-1.34)$ & $1.11(0.94-1.33)$ & \\
\hline Smoker & $1(1-2)$ & $1.34(1.09-1.65)$ & $1.36(1.12-1.65)$ & $1.35(1.12-1.64)$ & \\
\hline
\end{tabular}

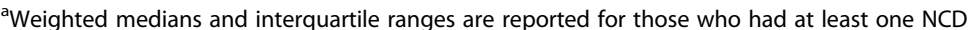

${ }^{\mathrm{b}}$ Adjusted for age, gender, marital status, rank, serving status, engagement type, service branch, deployment to Iraq or Afghanistan and primary role in parent unit

'Additionally adjusted for family relationship adversity in childhood

${ }^{\mathrm{d}}$ Additionally adjusted for alcohol misuse and smoking status 
Table 4 Cox proportional hazards models examining the associations with mental health, alcohol misuse, smoking for the top 5 NCDs

\begin{tabular}{|c|c|c|c|c|c|}
\hline & $\begin{array}{l}\text { n with disorder } \\
\text { (row \%) }\end{array}$ & $\begin{array}{l}\text { Unadjusted Hazard } \\
\text { Ratio (HR) }(95 \% \mathrm{Cl})\end{array}$ & $\begin{array}{l}\text { Adjusted HR } \\
(95 \% \mathrm{Cl})^{\mathrm{a}}\end{array}$ & $\begin{array}{l}\text { Adjusted HR } \\
(95 \% \mathrm{Cl})^{\mathrm{b}}\end{array}$ & $\begin{array}{l}\text { Adjusted HR } \\
(95 \% \mathrm{Cl})^{\mathrm{c}}\end{array}$ \\
\hline \multicolumn{6}{|c|}{ Gastrointestinal disorders $(n=8359$, failures $=303)$} \\
\hline \multicolumn{6}{|l|}{ PTSD } \\
\hline Non-case & $279(3.46 \%)$ & 1.00 & 1.00 & 1.00 & 1.00 \\
\hline Case & $21(7.58 \%)$ & $2.29(1.38-3.81)$ & $2.15(1.27-3.63)$ & $2.11(1.24-3.61)$ & $2.28(1.34-3.89)$ \\
\hline \multicolumn{6}{|l|}{ CMD } \\
\hline Non-case & $230(3.35 \%)$ & 1.00 & 1.00 & 1.00 & 1.00 \\
\hline Case & $72(4.85 \%)$ & $1.47(1.07-2.02)$ & $1.48(1.08-2.2)$ & $1.49(1.08-2.03)$ & $1.55(1.12-2.15)$ \\
\hline \multicolumn{6}{|l|}{ Alcohol misuse } \\
\hline Low risk drinking $(0-7)^{d}$ & $138(3.92 \%)$ & 1.00 & 1.00 & 1.00 & \\
\hline Hazardous drinking (8-15) & $130(3.51 \%)$ & $0.92(0.69-1.22)$ & $1.04(0.76-1.41)$ & $1.03(0.76-1.41)$ & \\
\hline $\begin{array}{l}\text { Harmful drinking/possible } \\
\text { dependence }(16+)\end{array}$ & $30(3.27 \%)$ & $0.89(0.56-1.41)$ & $1.10(0.68-1.77)$ & $1.07(0.65-1.77)$ & \\
\hline \multicolumn{6}{|l|}{ Binge drinking at phase 2} \\
\hline Monthly or less & $201(4.17 \%)$ & 1.00 & 1.00 & 1.00 & \\
\hline Weekly or more & $97(2.85 \%)$ & $0.70(0.52-0.93)$ & $0.76(0.56-1.03)$ & $0.76(0.56-1.03)$ & \\
\hline \multicolumn{6}{|l|}{ Smoking status at phase 2} \\
\hline Non-smoker & $134(2.96 \%)$ & 1.00 & 1.00 & 1.00 & \\
\hline Ex-smoker & $85(3.97 \%)$ & $1.32(0.96-1.82)$ & $1.18(0.85-1.64)$ & $1.17(0.84-1.63)$ & \\
\hline Smoker & $77(4.45 \%)$ & $1.56(1.12-2.16)$ & $1.65(1.19-2.28)$ & $1.64(1.18-2.28)$ & \\
\hline \multicolumn{6}{|c|}{ Joint disorders $(n=8361$, failures $=291)$} \\
\hline \multicolumn{6}{|l|}{ PTSD } \\
\hline Non-case & $272(3.34 \%)$ & 1.00 & 1.00 & 1.00 & 1.00 \\
\hline Case & $15(4.04 \%)$ & $1.23(0.67-2.26)$ & $1.23(0.66-2.27)$ & $1.18(0.64-2.17)$ & $1.07(0.57-1.99)$ \\
\hline \multicolumn{6}{|l|}{ CMD } \\
\hline Non-case & $224(3.31 \%)$ & 1.00 & 1.00 & 1.00 & 1.00 \\
\hline Case & $62(3.59 \%)$ & $1.08(0.77-1.52)$ & $1.06(0.76-1.49)$ & $1.05(0.74-1.47)$ & $1.00(0.70-1.43)$ \\
\hline \multicolumn{6}{|l|}{ Alcohol misuse } \\
\hline Low risk drinking $(0-7)^{d}$ & $117(3.18 \%)$ & 1.00 & 1.00 & 1.00 & \\
\hline Hazardous drinking (8-15) & $129(3.26 \%)$ & $1.04(0.77-1.39)$ & $0.98(0.72-1.33)$ & $0.97(0.71-1.32)$ & \\
\hline $\begin{array}{l}\text { Harmful drinking/possible } \\
\text { dependence }(16+)\end{array}$ & $42(4.55 \%)$ & $1.47(0.98-2.22)$ & $1.33(0.86-2.05)$ & $1.32(0.85-2.06)$ & \\
\hline \multicolumn{6}{|l|}{ Binge drinking at phase 2} \\
\hline Monthly or less & $169(3.09 \%)$ & 1.00 & 1.00 & 1.00 & \\
\hline Weekly or more & $118(3.86 \%)$ & $1.27(0.96-1.67)$ & $1.21(0.91-1.61)$ & $1.21(0.91-1.61)$ & \\
\hline \multicolumn{6}{|l|}{ Smoking status at phase 2} \\
\hline Non-smoker & $124(2.80 \%)$ & 1.00 & 1.00 & 1.00 & \\
\hline Ex-smoker & $78(3.52 \%)$ & $1.25(0.89-1.74)$ & $1.25(0.89-1.75)$ & $1.24(0.88-1.74)$ & \\
\hline Smoker & $85(4.43 \%)$ & $1.63(1.17-2.25)$ & $1.54(1.10-2.16)$ & $1.53(1.09-2.15)$ & \\
\hline \multicolumn{6}{|c|}{ Arthritis/osteoarthritis $(n=8484$, failures $=131)$} \\
\hline \multicolumn{6}{|c|}{ PTSD } \\
\hline Non-case & $120(1.49 \%)$ & 1.00 & 1.00 & 1.00 & 1.00 \\
\hline Case & $8(2.22 \%)$ & $1.55(0.68-3.52)$ & $1.76(0.77-4.02)$ & $1.78(0.79-4.01)$ & $1.73(0.71-4.20)$ \\
\hline
\end{tabular}


Table 4 Cox proportional hazards models examining the associations with mental health, alcohol misuse, smoking for the top 5 NCDs (Continued)

\begin{tabular}{|c|c|c|c|c|c|}
\hline & $\begin{array}{l}\text { n with disorder } \\
\text { (row \%) }\end{array}$ & $\begin{array}{l}\text { Unadjusted Hazard } \\
\text { Ratio (HR) }(95 \% \mathrm{Cl})\end{array}$ & $\begin{array}{l}\text { Adjusted HR } \\
(95 \% \mathrm{Cl})^{\mathrm{a}}\end{array}$ & $\begin{array}{l}\text { Adjusted HR } \\
(95 \% \mathrm{Cl})^{\mathbf{b}}\end{array}$ & $\begin{array}{l}\text { Adjusted HR } \\
(95 \% \mathrm{Cl})^{\mathrm{c}}\end{array}$ \\
\hline \multicolumn{6}{|l|}{ CMD } \\
\hline Non-case & $98(1.52 \%)$ & 1.00 & 1.00 & 1.00 & 1.00 \\
\hline Case & $31(1.65 \%)$ & $1.10(0.68-1.78)$ & $1.19(0.74-1.91)$ & $1.20(0.75-1.94)$ & $1.10(0.66-1.85)$ \\
\hline \multicolumn{6}{|l|}{ Alcohol misuse } \\
\hline Low risk drinking $(0-7)^{d}$ & $62(1.80 \%)$ & 1.00 & 1.00 & 1.00 & \\
\hline Hazardous drinking (8-15) & $55(1.34 \%)$ & $0.78(0.51-1.19)$ & $0.91(0.58-1.42)$ & $0.92(0.59-1.44)$ & \\
\hline $\begin{array}{l}\text { Harmful drinking/possible } \\
\text { dependence }(16+)\end{array}$ & $10(1.16 \%)$ & $0.70(0.33-1.49)$ & $0.95(0.44-2.09)$ & $0.99(0.44-2.20)$ & \\
\hline \multicolumn{6}{|l|}{ Binge drinking at phase 2} \\
\hline Monthly or less & $83(1.62 \%)$ & 1.00 & 1.00 & 1.00 & \\
\hline Weekly or more & $44(1.35 \%)$ & $0.86(0.56-1.33)$ & $0.98(0.63-1.53)$ & $0.99(0.64-1.55)$ & \\
\hline \multicolumn{6}{|l|}{ Smoking status at phase 2} \\
\hline Non-smoker & $57(1.36 \%)$ & 1.00 & 1.00 & 1.00 & \\
\hline Ex-smoker & $42(1.78 \%)$ & $1.27(0.80-2.03)$ & $1.09(0.67-1.77)$ & $1.09(0.67-1.76)$ & \\
\hline Smoker & $29(1.64 \%)$ & $1.26(0.75-2.11)$ & $1.33(0.78-2.27)$ & $1.34(0.78-2.29)$ & \\
\hline \multicolumn{6}{|c|}{ Hypertension $(n=8490$, failures $=105)$} \\
\hline \multicolumn{6}{|l|}{ PTSD } \\
\hline Non-case & $92(1.29 \%)$ & 1.00 & 1.00 & 1.00 & 1.00 \\
\hline Case & $11(2.82 \%)$ & $2.22(1.06-4.68)$ & $2.56(1.24-5.30)$ & $2.23(1.07-4.67)$ & $2.08(0.94-4.62)$ \\
\hline \multicolumn{6}{|l|}{ CMD } \\
\hline Non-case & $77(1.29 \%)$ & 1.00 & 1.00 & 1.00 & 1.00 \\
\hline Case & $27(1.75 \%)$ & $1.37(0.82-2.28)$ & $1.50(0.90-2.49)$ & $1.39(0.83-2.33)$ & $1.35(0.81-2.24)$ \\
\hline \multicolumn{6}{|l|}{ Alcohol misuse } \\
\hline Low risk drinking $(0-7)^{d}$ & $52(1.60 \%)$ & 1.00 & 1.00 & 1.00 & \\
\hline Hazardous drinking (8-15) & $41(1.22 \%)$ & $0.78(0.49-1.24)$ & $1.04(0.64-1.69)$ & $1.00(0.61-1.62)$ & \\
\hline $\begin{array}{l}\text { Harmful drinking/possible } \\
\text { dependence }(16+)\end{array}$ & $11(1.31 \%)$ & $0.86(0.42-1.77)$ & $1.54(0.74-3.18)$ & $1.39(0.67-2.91)$ & \\
\hline Binge drinking at phase 2 & $68(1.50 \%)$ & & & & \\
\hline Monthly or less & $36(1.23 \%)$ & 1.00 & 1.00 & 1.00 & \\
\hline Weekly or more & & $0.84(0.53-1.33)$ & $1.01(0.63-1.62)$ & $0.99(0.62-1.58)$ & \\
\hline \multicolumn{6}{|l|}{ Smoking status at phase 2} \\
\hline Non-smoker & $54(1.42 \%)$ & 1.00 & 1.00 & 1.00 & \\
\hline Ex-smoker & $28(1.50 \%)$ & $1.04(0.62-1.72)$ & $0.81(0.49-1.33)$ & $0.77(0.46-1.29)$ & \\
\hline Smoker & $22(1.23 \%)$ & $0.88(0.50-1.55)$ & $0.99(0.56-1.75)$ & $0.94(0.53-1.67)$ & \\
\hline \multicolumn{6}{|c|}{ Prostate and GU disorders ( $n=8469$, failures $=90$ ) } \\
\hline \multicolumn{6}{|l|}{ PTSD } \\
\hline Non-case & $80(1.08 \%)$ & 1.00 & 1.00 & 1.00 & 1.00 \\
\hline Case & $9(2.53 \%)$ & $2.42(1.08-5.41)$ & $2.50(1.14-5.46)$ & $2.17(0.97-4.85)$ & $2.47(1.17-5.20)$ \\
\hline \multicolumn{6}{|l|}{ CMD } \\
\hline Non-case & $64(1.00 \%)$ & 1.00 & 1.00 & 1.00 & 1.00 \\
\hline Case & $26(1.75 \%)$ & $1.77(1.04-3.00)$ & $1.82(1.09-3.05)$ & $1.74(1.05-2.89)$ & $1.80(1.08-3.01)$ \\
\hline \multicolumn{6}{|l|}{ Alcohol misuse } \\
\hline Low risk drinking $(0-7)^{d}$ & $(*)$ & 1.00 & 1.00 & 1.00 & \\
\hline
\end{tabular}


Table 4 Cox proportional hazards models examining the associations with mental health, alcohol misuse, smoking for the top 5 NCDs (Continued)

\begin{tabular}{|c|c|c|c|c|c|}
\hline & $\begin{array}{l}\text { n with disorder } \\
\text { (row \%) }\end{array}$ & $\begin{array}{l}\text { Unadjusted Hazard } \\
\text { Ratio (HR) }(95 \% \mathrm{Cl})\end{array}$ & $\begin{array}{l}\text { Adjusted HR } \\
(95 \% \mathrm{CI})^{\mathrm{a}}\end{array}$ & $\begin{array}{l}\text { Adjusted HR } \\
(95 \% \mathrm{CI})^{\mathrm{b}}\end{array}$ & $\begin{array}{l}\text { Adjusted HR } \\
(95 \% \mathrm{Cl})^{\mathrm{c}}\end{array}$ \\
\hline Hazardous drinking (8-15) & $(*)$ & $1.14(0.69-1.88)$ & $1.22(0.67-1.87)$ & $1.11(0.67-1.86)$ & \\
\hline $\begin{array}{l}\text { Harmful drinking/possible } \\
\text { dependence }(16+)\end{array}$ & $(*)$ & $0.61(0.25-1.49)$ & $0.64(0.25-1.66)$ & $0.61(0.24-1.59)$ & \\
\hline \multicolumn{6}{|l|}{ Binge drinking at phase 2} \\
\hline Monthly or less & $62(1.35 \%)$ & 1.00 & 1.00 & 1.00 & \\
\hline Weekly or more & $28(0.84 \%)$ & $0.63(0.38-1.06)$ & $0.63(0.37-1.08)$ & $0.63(0.37-1.07)$ & \\
\hline \multicolumn{6}{|l|}{ Smoking status at phase 2} \\
\hline Non-smoker & 39 (1.01\%) & 1.00 & 1.00 & 1.00 & \\
\hline Ex-smoker & $25(1.14 \%)$ & $1.12(0.61-2.02)$ & $1.00(0.54-1.83)$ & $0.98(0.54-1.80)$ & \\
\hline Smoker & $26(1.47 \%)$ & $1.51(0.86-2.66)$ & $1.35(0.74-2.46)$ & $1.37(0.78-2.42)$ & \\
\hline
\end{tabular}

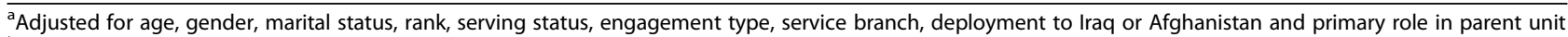
${ }^{\mathrm{b}}$ Additionally adjusted for family relationship adversity in childhood

${ }^{\mathrm{c} A d d i t i o n a l l y ~ a d j u s t e d ~ f o r ~ a l c o h o l ~ m i s u s e ~ a n d ~ s m o k i n g ~ s t a t u s ~ a t ~ p h a s e ~} 2$

${ }^{\mathrm{d} C a t e g o r y}$ includes the never drinkers due to low cell sizes

$\left(^{*}\right)$ - Numbers and percentages are not reported when $\mathrm{n}$ is smaller than 8 due to Hospital Episode Statistics reporting guidelines

\section{Age standardised comparisons with the general} population (per 1000 individuals)

Comparisons to HES data from the general population (standardised by age) showed that GI disorders (15.2 (military) vs 41.9 (gen pop) per 1000) and hypertension (22.8 vs 40.1 ) appeared to be more common in the general population, but joint problems (23.5 vs 7.4 ) and arthritis (19.9 vs 13.1), and prostate disorders (18.1 vs 7.4 , in males only) were more common in the military population (full details of these calculations available from the authors).

\section{Associations with number of NCDs reported}

Number of NCDs requiring a hospital admission was significantly associated with both CMD and probable PTSD, with a stronger association with probable PTSD. Current smokers reported a greater number of NCDs (Table 3).

\section{Alcohol, smoking and mental health as predictors of the top 5 NCDs \\ Gastrointestinal disorders}

Individuals with probable PTSD and/or CMD had 2 and 1.5 times the hazard, respectively, of having an

Table 5 Cox proportional hazards models examining the associations between change in CMD status and the NCD outcomes $(n=5794)$

\begin{tabular}{|c|c|c|c|c|c|c|}
\hline & & $\begin{array}{l}\text { Gastrointestinal } \\
\text { disorders } \\
\text { (failures = 229) }\end{array}$ & $\begin{array}{l}\text { Other joint } \\
\text { disorders } \\
\text { (failures = 196) }\end{array}$ & $\begin{array}{l}\text { Arthritis/ } \\
\text { osteoarthritis } \\
\text { (failures = 113) }\end{array}$ & $\begin{array}{l}\text { Hypertension } \\
\text { (failures = 92) }\end{array}$ & $\begin{array}{l}\text { Prostate and } \\
\text { other genitourinary } \\
\text { disease (failures }=65 \text { ) }\end{array}$ \\
\hline \multicolumn{7}{|l|}{ CMD change } \\
\hline \multirow[t]{4}{*}{ n (\%) } & Not a case stable & $137(59.45 \%)$ & $132(69.67 \%)$ & $74(69.09 \%)$ & $55(61.20 \%)$ & $39(59.89 \%)$ \\
\hline & Case stable & 29 (13.43\%) & $24(12.19 \%)$ & $14(9.32 \%)$ & $11(7.98 \%)$ & $12(16.04 \%)$ \\
\hline & Positive change & $32(12.96 \%)$ & $20(10.22 \%)$ & $11(11.66 \%)$ & $14(14.63 \%)$ & - \\
\hline & Negative change & $29(14.15 \%)$ & $15(7.92 \%)$ & $10(9.93 \%)$ & $11(16.19 \%)$ & $9(17.18 \%)$ \\
\hline \multirow[t]{4}{*}{ Unadjusted HR (95\% Cl) } & Not a case stable & 1.00 & 1.00 & 1.00 & 1.00 & 1.00 \\
\hline & Case stable & $1.93(1.28-2.93)$ & $1.44(0.91-2.28)$ & $1.55(0.86-2.81)$ & $1.65(0.83-3.29)$ & $2.11(1.08-4.12)$ \\
\hline & Positive change & $1.63(1.09-2.43)$ & $1.00(0.62-1.62)$ & $0.92(0.48-1.78)$ & $1.82(0.99-3.32)$ & - \\
\hline & Negative change & $1.59(1.05-2.42)$ & $0.75(0.43-1.30)$ & $1.03(0.53-2.02)$ & $1.53(0.79-2.96)$ & $1.59(0.76-3.34)$ \\
\hline \multirow[t]{4}{*}{ Fully adjusted HR (95\% Cl) } & Not a case stable & 1.00 & 1.00 & 1.00 & 1.00 & 1.00 \\
\hline & Case stable & $1.98(1.28-3.08)$ & $1.37(0.85-2.22)$ & $1.46(0.76-2.79)$ & $1.56(0.77-3.16)$ & $2.02(1.06-3.83)$ \\
\hline & Positive change & $1.65(1.10-2.49)$ & $0.99(0.60-1.64)$ & $1.03(0.52-2.01)$ & $1.69(0.89-3.21)$ & $0.47(0.13-1.65)$ \\
\hline & Negative change & $1.77(1.16-2.69)$ & $0.70(0.40-1.23)$ & $1.18(0.59-2.37)$ & $1.62(0.85-3.10)$ & $1.72(0.81-3.68)$ \\
\hline
\end{tabular}

$\mathrm{n}(\%)$ - unweighted frequencies and weighted percentages

Model 1 - unadjusted hazard ratios $(95 \% \mathrm{Cl})$

Model 2 - hazard ratios $(95 \% \mathrm{Cl})$ adjusted for age, gender, marital status, rank, serving status, engagement type, service branch, deployment to Iraq or

Afghanistan, primary role in parent unit and family relationship adversity in childhood, smoking status and alcohol use 
admission for a GI disorder in the fully adjusted model, compared to those without the mental disorder (Table 4). Smokers had 1.5 times the hazard of an admission for a GI disorder compared to non-smokers, after all adjustments. The analyses restricted to participants who completed both phases 1 and 2 examined change in CMD status across the same time period, as exposures for NCD admissions occurring after phase 2 (Table 5). Personnel with CMD at both phases, those who became a CMD case by phase 2 (i.e. did not meet criteria at phase 1 , but did by phase 2) and those who met CMD criteria at phase 1 only, had 2, 1.8 and 1.7 times the hazard, respectively, of having an admission for a GI disorder after phase 2 , in the fully adjusted models.

\section{Joint disorders}

Smokers had 1.5 times the hazard of having an admission for a joint disorder compared to non-smokers, in the fully adjusted model. No other exposures were statistically significantly associated (Tables 4 and 5).

\section{Arthritis/osteoarthritis}

There were no associations with mental health, alcohol and smoking status with admissions for arthritis or osteoarthritis (Tables $4 \& 5$ ).

\section{Hypertension}

There was a statistically significant association between probable PTSD and hypertension (with 2 times the hazard of an admission), in some adjusted models but this was no longer significant in the fully adjusted model (after adjustment for alcohol misuse and smoking status) (Table 4).

\section{Prostate or GU disorder}

Individuals with probable PTSD and CMD had 2.5 and 1.8 times the hazard of having an admission for a prostate or GU disorder, in the fully adjusted model (Table 4). Personnel who met criteria for CMD across both phases had 2 times the hazard for an admission for prostate or other GU disorders, in the fully adjusted model (Table 5), compared to those who did not meet criteria for CMD at either phase.

\section{Sensitivity analyses}

The results of the sensitivity analyses in the matched only sample $(n=6336)$ examining associations between alcohol, smoking and mental health and the top 5 NCDs showed very similar results to the reported results in the full sample, with very small differences in the size of the hazard ratios and no difference in the statistical significance of the findings (See Supplementary table 2).

\section{Discussion}

This is the first UK data linkage between a military cohort and secondary care records, and as far as we know is the first to link national healthcare records for England, Wales and Scotland together. The key finding is the prospective association between mental health and number of NCDs experienced which required a hospital admission, evidencing clear health inequalities compared to those with good mental health and the strong links between physical and mental health in this population. When examining specific NCDs, personnel with a mental disorder (probable PTSD or CMD) were found to be more likely to have admissions for GI disorders, hypertension and prostate \& GU disorders. Smokers were also more likely to have admissions for GI disorders and joint disorders. There was no evidence that alcohol misuse was associated with admissions for NCDs, during the timeframe of this study.

Most of the serving and ex-serving personnel in this study did not have a hospital admission for an NCD, which might be expected given the average age. For those who did, GI disorders were the most common, followed by joint disorders which were more common than in the general population. The findings on GI disorders correspond to a UK general population data linkage study of the Hertfordshire cohort study to EHRs in older adults, which showed that digestive diseases were one of the most common conditions requiring an admission in males [53]. In addition to joint disorders, arthritis was also common in the older age groups, and this would be expected given the physical demands of the military occupation. UK research has shown that musculoskeletal disorders are the most common cause of medical discharge [54] and US data have shown a higher prevalence of arthritis in veterans compared to non-veterans [55].

One of the reasons why there is more US data on physical conditions that require treatment is because service related disability determines access to healthcare services, unlike in the UK. This VA data has found that hypertension was the most common condition requiring healthcare services in ex-serving personnel [17], whereas this was the fourth most common NCD in this UK sample. Coronary heart disease was also common in the US VA data but not in the current study, which is likely to be explained by the average younger age of the current sample. Other conditions such as diabetes and hearing problems, which have previously been shown to be common in ex-serving personnel [17], were not captured in the current data, most likely because they will require treatment in primary care, rather than leading to a hospital admission.

Military personnel with a mental disorder appear to have an increased risk of hospital admission for NCDs, specifically GI disorders, hypertension and prostate and GU disorders. Given that our previous work has 
established that at least a fifth of the UK military have a mental disorder [29], this is a sizeable proportion of this population who have a greater need of inpatient care for these physical conditions. The association with mental disorder and NCDs was stronger and more consistent across conditions for probable PTSD than CMD, indicating that this disorder could have a greater impact on physical health, potentially resulting from dysregulation of the autonomic nervous system due to the linked trauma exposure [56]. There are additional mechanisms through which PTSD could impact on physical health, identified in previous research, including 1) the impact on the inflammatory system [57], 2) specific effects on the cardiovascular system [58] and 3) through generally worsened health behaviours in those with a mental disorder, for example, higher levels of alcohol and smoking [59]. In the current study there was only evidence that alcohol and smoking may partially explain the association between PTSD and hypertension, suggesting this may be one of the mechanisms leading to increased blood pressure. Our findings generally support other studies in veterans, e.g. finding an association between PTSD and an increased number of physical health conditions in veterans [60], and PTSD was associated with reports of physical comorbidity in Australian Vietnam veterans [16]. Specifically, there is strong evidence for the association between PTSD and hypertension [61], but our findings on the risk of GI disorders and prostate and GU disorders have not previously been shown. There is a wealth of data on the association between physical and mental health in the general population; a recent study using Scottish hospital records showed that individuals with a mental disorder were twice as likely to have an emergency hospital admission (non-psychiatric) compared to those without [62]. It should be acknowledged that the associations identified in this study may also reflect increased rates of healthcare use in individuals with a mental disorder [63], and not only poorer health; but the fact that associations were not consistent across all physical health outcomes suggests that we have identified more than just an increased propensity for help seeking.

This study did not find an association between alcohol misuse and hospital admissions for NCDs in military personnel. This contradicts previous findings on the longer term health risks of alcohol [64], but may only reflect the fact that the alcohol harms have not yet reached the severity that requires an admission. There is no doubt in the literature of the physical harms for those drinking at a problematic level. The most recent data from NHS Digital for alcohol related hospital admissions suggests that the spike is for 45 to 55 and 55 to 64 year olds [65], which is older than the average age for this sample. The lack of association for hypertension was unexpected, given this is classified as being partially attributed to alcohol [66], but less severe cases of hypertension are likely to be treated in primary care and there is also evidence that blood pressure can reduce after alcohol use has been reduced [66].

Researchers in the alcohol field promote taking a life course approach to account for the fact that alcohol use may vary over time [67], but this won't always capture the typical ups and downs of consumption that can occur between data collections. Particularly important for military personnel is the fact that they are more likely to have extended periods of abstention (for example, during deployments and advanced training operations) so their patterns of use may differ. Finally, being physically active may be protective against the health consequences of alcohol use e.g. for cancer [68], and given this population is likely to be physically active due to their occupation then this could explain these null effects. Further follow-up is required to see whether the association is stronger as these personnel age and reduce their levels of physical activity. In relation to other health behaviours, associations were found with smoking and the number of the NCDs requiring an admission, which is not a surprise, and the previous higher prevalence of smoking in military personnel $[26,27]$ has been proposed to explain the increased prevalence of coronary heart disease in this population [7].

\section{Strengths and weaknesses of the study}

This study analysed data from a large and representative military cohort study and it involved the first UK linkage of military health data to secondary care (i.e. hospital) EHRs. The benefits of using this data linkage approach is that we were able to get objective health data on a large population, without intensive tracing and biomedical interviews. However, due to the limitations of these data only having reliable diagnosis codes in the admitted patient care data, outcomes in this study were largely around conditions which required surgery or an inpatient stay [38]. The EHRs for outpatient appointments may have provided the broadest picture of chronic health conditions, and the number of events would have been greater than for inpatient events providing increased statistical power to study rarer conditions, but unfortunately these data did not have adequate recording of ICD-10 diagnoses. Future research should also explore the possibility of linkage to primary care records which would cover more chronic, long term health conditions, that don't require hospital care.

Health behaviours, including alcohol and smoking were self-reported in this study, which could result in a number of reporting biases (specifically under reporting of alcohol consumption given concerns about disclosing problems that may impact on career progression); however, alcohol 
misuse was assessed using a reliable and valid assessment tool [45] and other studies using the AUDIT have evidenced health risks for those drinking harmfully. The null findings for alcohol may relate to the lag time and age of the population and it is very possible that if we followed these individuals for another 10 to 20 years we may evidence an increase in alcohol related hospital admissions. Further limitations include the standardised comparisons to the general population, which couldn't account for both gender and age together due to the restrictions of the data published by NHS Digital. Finally, the military cohort study had a modest response rate and we were only able to gain matched data on $73 \%$ of the military cohort. We took what was felt to be the conservative option in treating those who were not matched as not having a hospital episode, given that those who required NHS treatment were more likely to have an NHS number and therefore have been matched. Furthermore, the main findings did not differ regardless of whether the matched or full sample was included in the analysis.

\section{Clinical implications}

These results provide strong evidence that within an AF population, those with a mental health problem have worse physical health. This highlights the priority to provide good mental healthcare and quick access to mental health services for serving personnel and veterans, to reduce the impact on their longer term physical health. The increased risk of hypertension for those with probable PTSD appeared to be partly explained by higher levels of smoking and alcohol use (given that the association attenuated after adjustment for these variables), suggesting that more effective health promotion and behaviour change interventions for those with a mental health problem may be required. Even though the prevalence of smoking is typically lower in the current UK military population compared to civilians, targeted interventions to encourage cessation in those who do smoke will have positive health consequences.

\section{Conclusions}

Military personnel with a mental health problem are more likely to have an inpatient hospital admission for NCDs compared to those without, specifically for gastrointestinal disorders, hypertension and prostrate and GU disorders. For hypertension, this increased risk appears to be partially driven by poorer health behaviours. This study has shown that it is feasible to link a military cohort to admitted patient care records from England, Wales and Scotland and to identify which conditions most commonly require inpatient care in this population.

\section{Supplementary information}

Supplementary information accompanies this paper at https://doi.org/10. 1186/s12889-020-09300-5.

Additional file 1: Supplementary Table 1. Comparing personnel who were matched and unmatched to English, Scottish or Welsh electronic healthcare records. Supplementary Table 2. Cox proportional hazards models examining the associations with mental health, alcohol misuse, smoking for the top 5 NCDs (restricted to the matched sample).

Additional file 2. Supplementary file 1. Developing a framework of non-communicable physical diseases.

Additional file 3. Supplementary figure 1. Figure showing data linkage of the KCMHR cohort data to the electronic healthcare records.

\section{Abbreviations}

NCD: Non-communicable disease; PTSD: Post-traumatic stress disorder; CMD: Common mental disorder; EHR: Electronic healthcare records; NHS: National health services; KCMHR: King's centre for military health research; HR: Hazard ratio; Cl: Confidence intervals

\section{Acknowledgements}

We would like to thank Dave Rutter from the Department of Health and Dr. Beverly Bergman from the University of Glasgow who both provided invaluable support and advice throughout this research study. We would also like to thank the military personnel who generously gave their time to participate in the cohort study.

\section{Authors' contributions}

LG, NTF and SW conceived the design of this study with additional advice from $S L, R D H, M J$ and PMC. LG, DL and ZC conducted the data analyses and all authors contributed to the interpretation of the data, to the drafting of this work and have approved the final draft of this manuscript.

\section{Funding}

This work was funded by the Economic and Social Research Council (grant number ES/L014521/1), DL and ZC were funded by the grant. The funder was independent of this research and did not contribute to the design of the study and collection, analysis, interpretation of data and to writing the manuscript. RDH was funded by a Medical Research Council (MRC)

Population Health Scientist Fellowship (grant number MR/J01219X/1). RDH and SL have received salary support from the National Institute for Health Research (NIHR) Mental Health Biomedical Research Centre at South London and Maudsley NHS Foundation Trust and King's College London. SW receives funding from the Ministry of Defence. MJ salary is fully supported by a grant from Ministry of Defence.

\section{Availability of data and materials}

The data that support the findings of this study are available from NHS Digital for England, NHS Information Services for Wales and Information Division Services for Scotland for the electronic healthcare records and from King's Centre for Military Health Research for the cohort data, but restrictions apply to the availability of these data, which were used under license for the current study, and so are not publicly available. Data are however available from the authors upon reasonable request and with permission of NHS Digital, NHS Information Services for Wales, Information Division Services for Scotland and King's Centre for Military Health Research.

\section{Ethics approval and consent to participate}

This study received ethical approval from the London-Dulwich NHS Research Ethics Committee in November 2014 (REC no: 07/Q0703/36) and Section 251 approval from the Health Research Authority (Ref: 15/CAG/0136). Participants provided written consent to participate in the KCMHR cohort study and additional written consent to access their electronic healthcare records. 


\section{Competing interests}

$\mathrm{RDH}$ has received research funding from Roche, Pfizer, Janssen and Lundbeck. SW is a Trustee of Combat Stress and Honorary Consultant Advisor in Psychiatry to the British Army. This work was undertaken prior to NTF's appointment to the Independent Group Advising on the Release of Data. NTF is a trustee of The Warrior Programme. DL, ZC, SL, PM, MJ and LG declare that they have no competing interests.

\section{Author details}

'Department of Psychology, University of Liverpool, Room 2.31 Eleanor Rathbone Building, Liverpool L69 7ZA, UK. ${ }^{2}$ King's Centre for Military Health Research, Institute of Psychiatry, Psychology \& Neuroscience, King's College London, London, UK. ${ }^{3}$ Liverpool Centre for Alcohol Research, Liverpool Health Partners, Liverpool, UK. ${ }^{4}$ Biostatistics \& Health Informatics, Institute of Psychiatry, Psychology \& Neuroscience, King's College London, London, UK. 5 Institute for Lifecourse Development, University of Greenwich, London, UK. ${ }^{6}$ Psychological Medicine, Institute of Psychiatry, Psychology \& Neuroscience, King's College London, London, UK. ${ }^{7}$ Academic Department of Military Mental Health, Institute of Psychiatry, Psychology \& Neuroscience, King's College London, London, UK.

\section{Received: 2 March 2020 Accepted: 26 July 2020}

Published online: 10 September 2020

\section{References}

1. Fear NT, Jones M, Murphy D, Hull L, Iversen AC, Coker B, et al. What are the consequences of deployment to Iraq and Afghanistan on the mental health of the UK armed forces? A cohort study. Lancet. 2010;375(9728):1783-97.

2. Hoge C, Auchterlonie J, Milliken C. Mental health problems, use of mental health services, and attrition from military service after returning from deployment to Iraq or Afghanistan. JAMA. 2006;295(9):1023-32.

3. Forbes H, Jones N, Woodhead C, Greenberg N, Harrison K, White S, et al. What are the effects of having an illness or injury whilst deployed on post deployment mental health? A population based record linkage study of UK Army personnel who have served in Iraq or Afghanistan. BMC Psychiatry. 2012;12(1):178.

4. Falvo MJ, Serrador JM, McAndrew LM, Chandler HK, Lu S-E, Quigley KS. A retrospective cohort study of U.S. service members returning from Afghanistan and Iraq: is physical health worsening over time? BMC Public Health. 2012;12(1):1-7.

5. Department of Veterans Affairs. Mortality rates and life expectancy of veterans from 1980 to 2014, and by education and income. Washington DC: National Center for Veterans Analysis and Statistics; 2017.

6. Kramarow E, Pastor P. The health of male veterans and nonveterans aged 25-64: United States, 2007-2010. NCHS data brief, no 101. Hyattsville: National Center for Health Statistics; 2012.

7. Bergman BP, Mackay DF, Pell JP. Acute myocardial infarction in Scottish military veterans: a retrospective cohort study of 57,000 veterans and 173,000 matched nonveterans. Am J Epidemiol. 2014;179(12):1434-41.

8. Lynch P. Coronary risk profile of young soldiers with coronary heart disease. J R Army Med Corps. 1985;131(1):38-41.

9. Centers for Disease Control and Prevention. Veterans Have Higher Arthritis Rates Than Civilians. JAMA. 2015;313(3):236.

10. McLaughlin R, Nielsen $L$, Waller M. An evaluation of the effect of military service on mortality: quantifying the healthy soldier effect. Ann Epidemiol. 2008;18(12):928-36.

11. Macfarlane GJ, Thomas E, Cherry N. Mortality among UK gulf war veterans. Lancet. 2000;356(9223):17-21.

12. Macfarlane GJ, Biggs A-M, Maconochie N, Hotopf M, Doyle P, Lunt M. Incidence of cancer among UK gulf war veterans: cohort study. J Epidemiol Community Health. 2004;58(4):339.

13. Boehmer TKC, Flanders WD, McGeehin MA, Boyle C, Barrett DH. Postservice mortality in Vietnam veterans: 30-year follow-up. Arch Intern Med. 2004; 164(17):1908-16.

14. World Health Organisation. Global status report on noncommunicable diseases 2010: description of the global burden of NCDs, their risk factors and determinants. Switzerland: WHO; 2011.

15. Seal KH, Bertenthal D, Miner CR, Sen S, Marmar C. Bringing the war back home: mental health disorders among 103788 us veterans returning from Iraq and Afghanistan seen at department of veterans affairs facilities. Arch Intern Med. 2007;167(5):476-82.
16. McLeay SC, Harvey WM, Romaniuk MN, Crawford DH, Colquhoun DM Young RM, et al. Physical comorbidities of post-traumatic stress disorder in Australian Vietnam war veterans. Med J Aust. 2017;206(6):251-7.

17. Yu W, Ravelo A, Wagner TH, Phibbs CS, Bhandari A, Chen S, et al. Prevalence and costs of chronic conditions in the VA health care system. Med Care Res Rev. 2003;60(3 suppl):146S-67S.

18. Thomas MM, Harpaz-Rotem I, Tsai J, Southwick SM, Pietrzak RH. Mental and Physical Health Conditions in US Combat Veterans: Results From the National Health and Resilience in Veterans Study. Prim Care Companion CNS Disord. 2017;19(3):17m02118.

19. Solomon Z, Levin Y, Assayag EB, Furman O, Shenhar-Tsarfaty S, Berliner S, et al. The implication of combat stress and PTSD trajectories in metabolic syndrome and elevated C-reactive protein levels: a longitudinal study. J Clin Psychiatry. 2017;78(9):e1180-e6.

20. Dominick KL, Golightly YM, Jackson GL. Arthritis prevalence and symptoms among US non-veterans, veterans, and veterans receiving Department of Veterans Affairs Healthcare. J Rheumatol. 2006;33(2):348-54.

21. Goodwin L, Bourke J, Forbes H, Hotopf M, Hull L, Jones N, et al. Irritable bowel syndrome in the UK military after deployment to Iraq: what are the risk factors? Soc Psychiatry Psychiatr Epidemiol. 2013;48(11):1755-65.

22. Barboza Solís $C$, Kelly-Irving $M$, Fantin $R$, Darnaudéry $M$, Torrisani J, Lang $T$, et al. Adverse childhood experiences and physiological wear-and-tear in midlife: findings from the 1958 British birth cohort. Proc Natl Acad Sci. 2015; 112(7):E738-E46

23. Fear NT, Iversen A, Meltzer H, Workman L, Hull L, Greenberg N, et al. Patterns of drinking in the UK armed forces. Addiction. 2007;102(11):1749-59.

24. Jacobson IG, Ryan MK, Hooper TI, et al. ALcohol use and alcohol-related problems before and after military combat deployment. JAMA. 2008;300(6): 663-75.

25. Rehm J, Mathers C, Popova S, Thavorncharoensap M, Teerawattananon Y, Patra J. Global burden of disease and injury and economic cost attributable to alcohol use and alcohol-use disorders. Lancet. 2009;373(9682):2223-33.

26. Hoerster KD, Lehavot K, Simpson T, McFall M, Reiber G, Nelson KM. Health and health behavior differences: U.S. military, veteran, and civilian men. Am J Prev Med. 2012;43(5):483-9.

27. Fear NT, Horn O, Hull L, Murphy D, Jones M, Browne T, et al. Smoking among males in the UK armed forces: changes over a seven year period. Prev Med. 2010;50(5-6):282-4.

28. Nguyen X-MT, Quaden RM, Wolfrum S, Song RJ, Yan JQ, Gagnon DR, et al. Prevalence of ideal cardiovascular health metrics in the million veteran program. Am J Cardiol. 2018;122(2):347-52.

29. Goodwin L, Wessely S, Hotopf M, Jones M, Greenberg N, Rona RJ, et al. Are common mental disorders more prevalent in the UK serving military compared to the general working population? Psychol Med. 2015;45(09):1881-91.

30. Fetzner MG, McMillan KA, Asmundson GJG. Similarities in specific physical health disorder prevalence among formerly deployed Canadian forces veterans with full and subsyndromal PTSD. Depress Anxiety. 2012;29(11):958-65.

31. Koenen KC, Sumner JA, Gilsanz P, Glymour MM, Ratanatharathorn A, Rimm EB, et al. Post-traumatic stress disorder and cardiometabolic disease: improving causal inference to inform practice. Psychol Med. 2016;47(2):209-25.

32. Cuijpers P, Vogelzangs N, Twisk J, Kleiboer A, Li J, Penninx BW. Comprehensive meta-analysis of excess mortality in depression in the general community versus patients with specific illnesses. Am J Psychiatry. 2014;171(4):453-62.

33. McKenzie DP, Sim MR, Clarke DM, Forbes AB, Ikin JF, Kelsall HL. Developing a brief depression screen and identifying associations with comorbid physical and psychological illness in Australian gulf war veterans. J Psychosom Res. 2015;79(6):566-73.

34. Patten SB, Williams JVA, Lavorato DH, Modgill G, Jetté N, Eliasziw M. Major depression as a risk factor for chronic disease incidence: longitudinal analyses in a general population cohort. Gen Hosp Psychiatry. 2008; 30(5):407-13

35. Win S, Parakh K, Eze-Nliam CM, Gottdiener JS, Kop WJ, Ziegelstein RC. Depressive symptoms, physical inactivity and risk of cardiovascular mortality in older adults: the cardiovascular health study. Heart. 2011;97(6):500-5.

36. Trivedi RB, Post EP, Sun H, Pomerantz A, Saxon AJ, Piette JD, et al. Prevalence, comorbidity, and prognosis of mental health among US veterans. Am J Public Health. 2015;105(12):2564-9.

37. Hotopf M, Hull L, Fear NT, Browne T, Horn O, Iversen A, et al. The health of UK military personnel who deployed to the 2003 Iraq war: a cohort study. Lancet. 2006;367(9524):1731-41. 
38. Leightley D, Chui Z, Jones M, Landau S, McCrone P, Hayes RD, et al. Integrating electronic healthcare records of armed forces personnel: developing a framework for evaluating health outcomes in England, Scotland and Wales. Int J Med Inform. 2018;113:17-25.

39. Iversen AC, Fear NT, Simonoff E, Hull L, Horn O, Greenberg N, et al. Influence of childhood adversity on health among male UK military personnel. Br J Psychiatry. 2007;191(6):506-11.

40. Felitti VJ, Anda RF, Nordenberg D, Williamson DF, Spitz AM, Edwards V, et al. Relationship of childhood abuse and household dysfunction to many of the leading causes of death in adults: the adverse childhood experiences (ACE) study. Am J Prev Med. 1998;14(4):245-58.

41. Goldberg DP, Gater R, Sartorius N, Ustun TB, Piccinelli M, Gureje O, et al. The validity of two versions of the GHQ in the WHO study of mental illness in general health care. Psychol Med. 1997;27(01):191-7.

42. Hardy GE, Shapiro DA, Haynes CE, Rick JE. Validation of the general health Questionnaire-12: using a sample of employees from England's health care services. Psychol Assess. 1999;11(2):159-65.

43. American Psychiatric Association. Diagnostic and statistical manual of mental disorders. 4th ed. Washington, DC: American Psychiatric Association; 1994.

44. Weathers F, Litz B, Herman D, Huska J, Keane T. The PTSD checklist - civilian version (PCL-C). Boston: National Centre for PTSD; 1994.

45. Babor T, Higgins-Biddle J, Saunders J, Monteiro M. AUDIT. The alcohol use disorders identification test. Geneva: Department of Mental Health and Substance Dependence, WHO; 2001.

46. A clinical follow-up study of reserve forces personnel treated for mental health problems following demobilisation. J Ment Health.20(2):136-45.

47. World Health Organization. The ICD-10 classification of mental and behavioural disorders: clinical descriptions and diagnostic guidelines. Geneva: WHO; 1992.

48. Lyons RA, Jones KH, John G, Brooks CJ, Verplancke J-P, Ford DV, et al. The SAIL databank: linking multiple health and social care datasets. BMC Med Inform Decis Making. 2009;9(1):1-8.

49. Health and Social Care Information Centre. Hospital Episode Statistics (HES): Improving the quality and value of hospital data. Leeds: HSCIC; 2011.

50. StataCorp. Stata Statistical Software: Release 14. College Station: Stata Corporation; 2015.

51. NHS Digital. Hospital episode statistics (HES) analysis guide. London: National Statistics; 2019.

52. Rao JNK, Scott AJ. On chi-squared tests for multiway contingency tables with cell proportions estimated from survey data. Ann Stat. 1984;12(1):46-60.

53. Simmonds SJ, Syddall HE, Walsh B, Evandrou M, Dennison EM, Cooper C, et al. Understanding NHS hospital admissions in England: linkage of hospital episode statistics to the Hertfordshire cohort study. Age Ageing. 2014;43(5): 653-60.

54. Williamson V, Diehle J, Dunn R, Jones N, Greenberg N. The impact of military service on health and well-being. Occup Med (Oxford). 2019;69(1): 64-70.

55. Murphy LB, Helmick CG, Allen KD, Theis KA, Baker NA, Murray GR, et al. Arthritis among veterans - United States, 2011-2013. Morb Mortal Wkly Rep. 2014;63(44):999-1003.

56. McFarlane AC. The long-term costs of traumatic stress: intertwined physical and psychological consequences. World Psychiatry. 2010;9(1):3-10.

57. Hori H, Kim Y. Inflammation and post-traumatic stress disorder. Psychiatry Clin Neurosci. 2019;73(4):143-53.

58. Coughlin SS. Post-traumatic stress disorder and cardiovascular disease. Open Cardiovasc Med J. 2011;5:164-70

59. Debell F, Fear NT, Head M, Batt-Rawden S, Greenberg N, Wessely S, et al. A systematic review of the comorbidity between PTSD and alcohol misuse. Soc Psychiatry Psychiatr Epidemiol. 2014;49(9):1401-25.

60. El-Gabalawy R, Blaney C, Tsai J, Sumner JA, Pietrzak RH. Physical health conditions associated with full and subthreshold PTSD in U.S. military veterans: Results from the National Health and Resilience in Veterans Study. J Affect Disord. 2018;227:849-53.

61. Abouzeid M, Kelsall HL, Forbes AB, Sim MR, Creamer MC. Posttraumatic stress disorder and hypertension in Australian veterans of the 1991 gulf war. J Psychosom Res. 2012;72(1):33-8.

62. Payne RA, Abel GA, Guthrie B, Mercer SW. The effect of physical multimorbidity, mental health conditions and socioeconomic deprivation on unplanned admissions to hospital: a retrospective cohort study. Can Med Assoc J. 2013;185(5):E221-E8.
63. Berghöfer A, Roll S, Bauer M, Willich SN, Pfennig A. Screening for depression and high utilization of health care resources among patients in primary care. Community Ment Health J. 2014;50(7):753-8.

64. World Health Organisation. Global status report on alcohol and health 2014 Switzerland: WHO; 2014.

65. NHS Digital. Statistics on alcohol, England 2019. London: National Statistics; 2019.

66. Rehm J, Gmel GE, Gmel G, Hasan OSM, Imtiaz S, Popova S, et al. The relationship between different dimensions of alcohol use and the burden of disease_-an update. Addiction. 2017;112(6):968-1001.

67. Britton A, Ben-Shlomo Y, Benzeval M, Kuh D, Bell S. Life course trajectories of alcohol consumption in the United Kingdom using longitudinal data from nine cohort studies. BMC Med. 2015;13(1):1-9.

68. Perreault K, Bauman A, Johnson N, Britton A, Rangul V, Stamatakis E. Does physical activity moderate the association between alcohol drinking and allcause, cancer and cardiovascular diseases mortality? A pooled analysis of eight British population cohorts. Br J Sports Med. 2017;51(8):651-7.

\section{Publisher's Note}

Springer Nature remains neutral with regard to jurisdictional claims in published maps and institutional affiliations.
Ready to submit your research? Choose BMC and benefit from:

- fast, convenient online submission

- thorough peer review by experienced researchers in your field

- rapid publication on acceptance

- support for research data, including large and complex data types

- gold Open Access which fosters wider collaboration and increased citations

- maximum visibility for your research: over $100 \mathrm{M}$ website views per year

At $\mathrm{BMC}$, research is always in progress.

Learn more biomedcentral.com/submissions 